\title{
Two-phase Flow Behaviour in Airlift Pumps
}

\author{
Rashal Abed, Eric Chadwick, Wael H. Ahmed \\ University of Guelph \\ 50 Stone Rd E, Guelph, Canada \\ rabed@uoguelph.ca; echadwic@uoguelph.ca; ahmedw@uoguelph.ca
}

\begin{abstract}
Airlift pumps use buoyant forces to displace liquid in vertical pipes. In this paper, the performance of a new design of airlift pump has been investigated. This new design uses both axial and radial injectors to improve the pump performance. The behaviour of two-phase flow under different operating conditions of the pump is discussed. These include the effect of submergence ratio, air flow rate and void fraction on the pump efficiency. Flow visualization images are used to describe the two-phase flow patterns and their effect on the pump performance. It was clear from the present experiments that the pump operating at higher submergence ratios found to deliver higher water flow rates and better efficiencies. The void fraction was found to increase throughout the different flow patterns observed in the pipe riser while the water flow rate remained approximately constant.
\end{abstract}

Keywords: Airlift Pump, Air Injection, Two-Phase Flow, Void Fraction, Performance.

\section{Introduction}

Airlift pumps use injected compressed air to displace a liquid in a vertical pipe. The air injected at the bottom of a vertical riser decreases the average specific gravity of the fluid in the vertical column allowing the mixture to move upward [1]. In an ideal situation, the injected gas creates piston-like bubbles and transports the liquid under the buoyancy effect. The simplicity and low maintenance of such pumps allow for a wider application range especially when aeration is also needed. In applications in which corrosive fluids need to be displaced or where pre-existing compressed air is available, airlift pumps represent a more desired choice [2-4]. Despite their proven potential, the performance of airlift pumps has yet to be fully optimized. This study focuses on a new design of the airlift developed by Ahmed and Badr [1]. In this design, air is injected both in radial and axial geometries at the bottom of the pipe riser. These two separate components allow for optimal water flow rates when air is injected in different quantities through the two injections. Experiments have been performed and analysed in this paper in order to highlight the effects of various submergence ratios on the overall performance of the airlift pump.

\section{Experimental Setup and Pump Design}

Figure 1 shows an illustration of the experimental setup. The pump consists of an air injector with both axial and radial geometries connected to a riser pipe of inner diameter $25.4 \mathrm{~mm}$ and a length of $1.76 \mathrm{~m}$. This riser pipe passes through the delivery tank, where the air separated and the water is transferred to the collecting tank for measurement. The pump suction line is connected a water reservoir. The reservoir is a $40 \mathrm{~L}$ tank that consists of two equal sections: the supply tank and the overflow tank. The supply tank consists of an inlet which expands into a 6-inch $(0.1524 \mathrm{~m})$ inner diameter pipe filled with rocks to reduce turbulence in the reservoir and maintain steady water level. The water flows out of this larger pipe and into the supply tank until it reaches the top of the divider and pours into the overflow tank. This design ensures the water level in the riser pipe remains constant during the experiments. The reservoir tank is attached to the frame and its position can be adjusted to allow for testing different submergence ratios $\left(\mathrm{H}_{\mathrm{s}} / \mathrm{L}\right)$. For this study, the performance of the pump will be compared at two different submergence ratios: 0.5 and 0.9. All pipes were manufactured from transparent materials to allow for observation of two-phase flow patterns.

The compressed air is supplied by a central utility plan and kept at a constant pressure using a pressure regulator. The air is delivered by $6 \mathrm{~mm}$ inner diameter hosing to the injector at both its radial and axial geometries. Before reaching the injector, the air passes through, two on/off valves, a pressure regulator, a needle valve for flow control, and two digital mass flow controls. These mass flowmeters are used to record the air flow rate as well as the temperature of the incoming 
air. The pressure due to the head in the riser pipe along with this temperature is used to calculate the pressure of the air and subsequently the mass flow rate of air in each experiment.

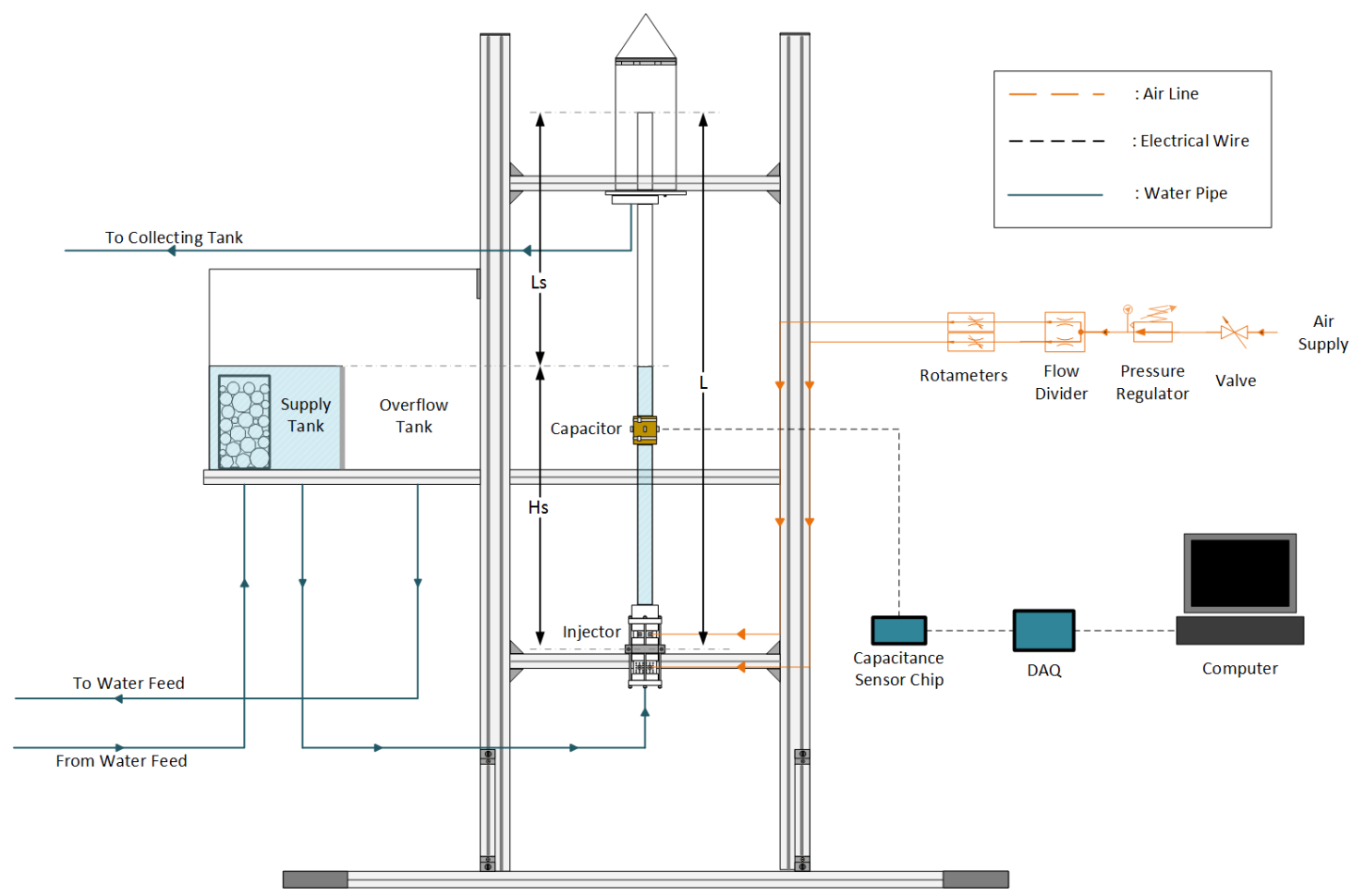

Fig. 1: Schematic Diagram of Experimental Setup.

A single injector is used in the experiments consisting of two geometries of air inlets. This injector is attached to the end of the riser pipe and supplied with air via the compressor at the central utilities plant at the University of Guelph. The dual injector was designed by Ahmed and Badr [1] and consists of a radial and axial injection inlet. Each inlet is connected to a separate needle valve and flow meter so that one or both injection methods can be used. At the radial inlet, the air enters a compartment surrounding a perforated tube of the same diameter as the riser pipe. The perforation can be described as 180 holes of $1.7 \mathrm{~mm}$ diameter distributed uniformly around the circumference of the pipe. At the axial geometry, a stainless-steel liner of annular clearance $1.5 \mathrm{~mm}$ forces the flow of air upward along the walls of the riser pipe. In this study, the pump efficiency is calculated based on a modified definition of Nicklin as follows [5].

$$
\eta=\frac{\rho g Q_{L}\left(L-H_{S}\right)}{P_{a t m} Q_{G} \ln \left(\frac{P_{\text {in }}}{P_{a t m}}\right)}
$$

where $\mathrm{Q}_{\mathrm{L}}$ is the water discharge, $\mathrm{Q}_{\mathrm{G}}$ is the volumetric flow rate of air, $\mathrm{P}_{\mathrm{in}}$ is the injection pressure of air and $\mathrm{P}_{\mathrm{atm}}$ is the atmospheric pressure. The variables $\mathrm{L}$ and $\mathrm{H}_{\mathrm{s}}$ are the length of the riser pipe and the static head respectively. They are also defined visually in Figure 1.

In this study, a capacitance sensor is used to record the void fraction of the two-phase flow in the pump riser. The detailed design of this capacitance sensor is explained by Ahmed [6]. The sensor is connected to a capacitance meter and a DAQ to record the dynamic void fraction signal. Void fraction data are collected at a sampling frequency of $2.5 \mathrm{kHz}$ and for a period of $100 \mathrm{sec}$ to insure that the signal adequately present all variations in the void fraction. Prior to each experiment, static calibration of the sensor is completed. The capacitance values at this section of the pipe are reordered when the pipe is completely empty and full of water. The capacitance recorded when only air is present relates to $100 \%$ 
void fraction, while the capacitance recorded when only water is present relates to $0 \%$ void fraction. Deionized water is used for all experiments to keep the system rid of contaminants and mineral deposits.

The two mass-flow meters used in these experiments have a $0.8 \%$ error reading along with a $\pm 0.2 \%$ full scale for the range of 0-500 LPM. The stopwatch used to determine the water flow rate was measured in increments of 1 millisecond, while the collection tank used to determine the volume of water was measured in increments of $1 \mathrm{~L}$. From this, the uncertainty of these experiments were calculated to be $10 \%$ for $\mathrm{Q}_{\mathrm{L}}(\mathrm{LPM})$ and $1.2 \%$ for $\mathrm{Q}_{\mathrm{a}}(\mathrm{LPM})$.

\section{Results and Discussion}

To evaluate the performance of the airlift pump at various submergence ratios, numerous experiments were performed. Experiments are performed to evaluate the effect of changing submergence levels for the same air injection. For dual injection, air is injected radially and axially as explained by Ahmed and Badr [1]. Both axial and radial injection sites receive the same air mass flow rate during dual injection. This specific injection type was compared between submergence ratios of 0.5 and 0.9 . Figure 2 shows the performance curve of the airlift pump at a submergence of 0.5. As shown in the figure, as air flow rate is increased, water flow rate increases continuously until reaching approximately a constant value before slightly decreasing. The first data point indicating any water flow rate indicates the air flow rate that first achieved any water reaching the required lift. From 0 to approximately $1.029 \mathrm{~kg} / \mathrm{hr}$ there was no observable water flow rate at a 0.5 submergence. This is because the buoyant force of the air bubbles is not enough to lift any amount of water to the top part of the pump riser. Although the water flow rate does increase slightly beyond the best efficiency range of the pump, the efficiency drops more drastically as the air flow rate increases.

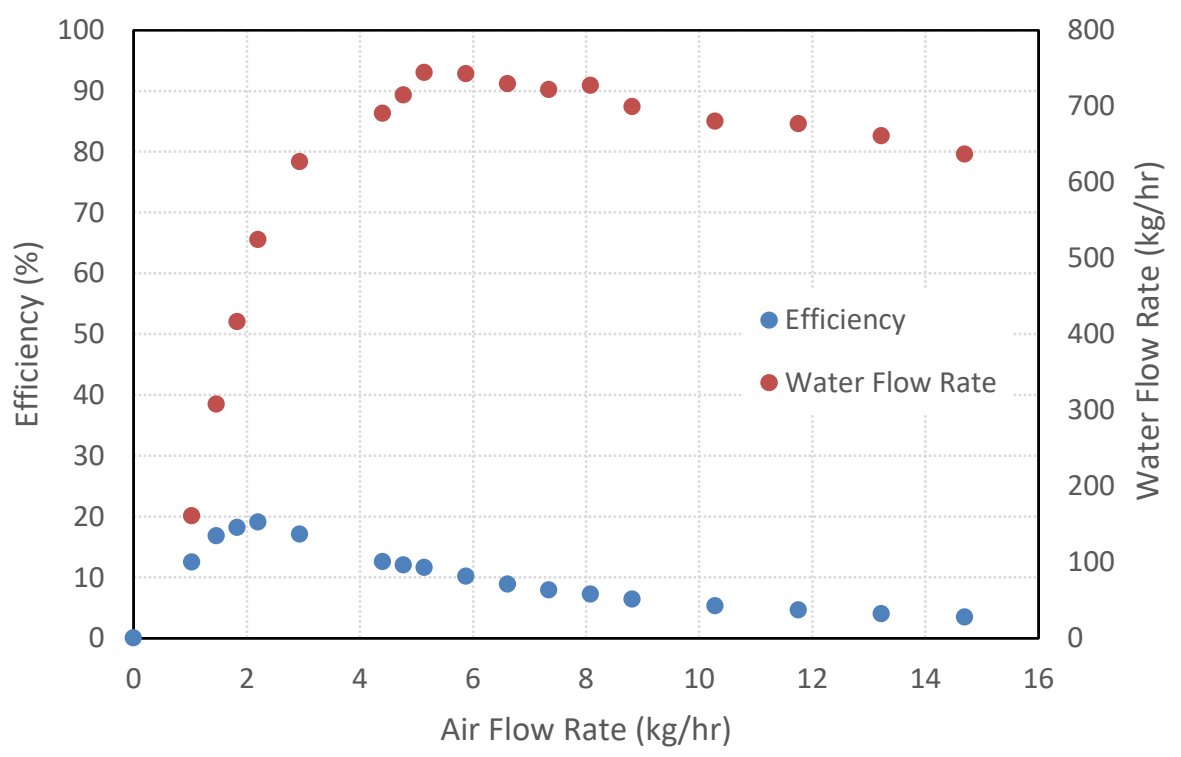

Fig. 2: Performance of Airlift Pump for steady dual injection at 0.5 submergence ratio.

For this experimental setup, the amount of work required is directly proportional to the static head $\left(\mathrm{H}_{\mathrm{s}}\right)$ of water in the riser pipe. The static head is also proportional to the submergence ratio $\left(\mathrm{H}_{\mathrm{s}} / \mathrm{L}_{\mathrm{s}}\right)$. As the static head increases, less work is required to lift the water to the desired height. In other words, as the submergence ratio increases, the water mass flow rate and efficiency increases at the same air mass flow rates. Figures 2 and 4 show dual injection performance for submergence ratios of 0.5 and 0.9 respectively. As can be observed, similar patterns are seen in these water flow rate curves as they were at 0.5 submergence ratio: water flow rates increasing continuously until reaching a peak flow rate, at which the trend starts to decrease steadily. Likewise, water flow rates do not appear to increase by significant amounts after passing the highest efficiencies. The most notable difference in both figures is that as expected, water flow rate and efficiency have increased greatly at a submergence of 0.9 . The water flow rates experienced similar increases as can be observed in the figures. 
Figure 3 and 5 displays the void fraction at each air flow rate collected at the two different submergence ratios. These measurements of void fraction were collected to quantify the ration between air and water in the pipe riser. As can be seen in the figures, both trend lines follow a similar pattern of constant increase as the air flow rate is raised. The main difference between the void fraction curve for the 0.5 and the 0.9 submergence, is the wider range of values that was collected at the 0.9 level. Although both submergence ratios received the same air flow rates, it was not until an air flow rate of $1.029 \mathrm{~kg} / \mathrm{hr}$ was injected that any observable water flow occurred, hence the data collection began at a much later point than that of the 0.9 submergence.

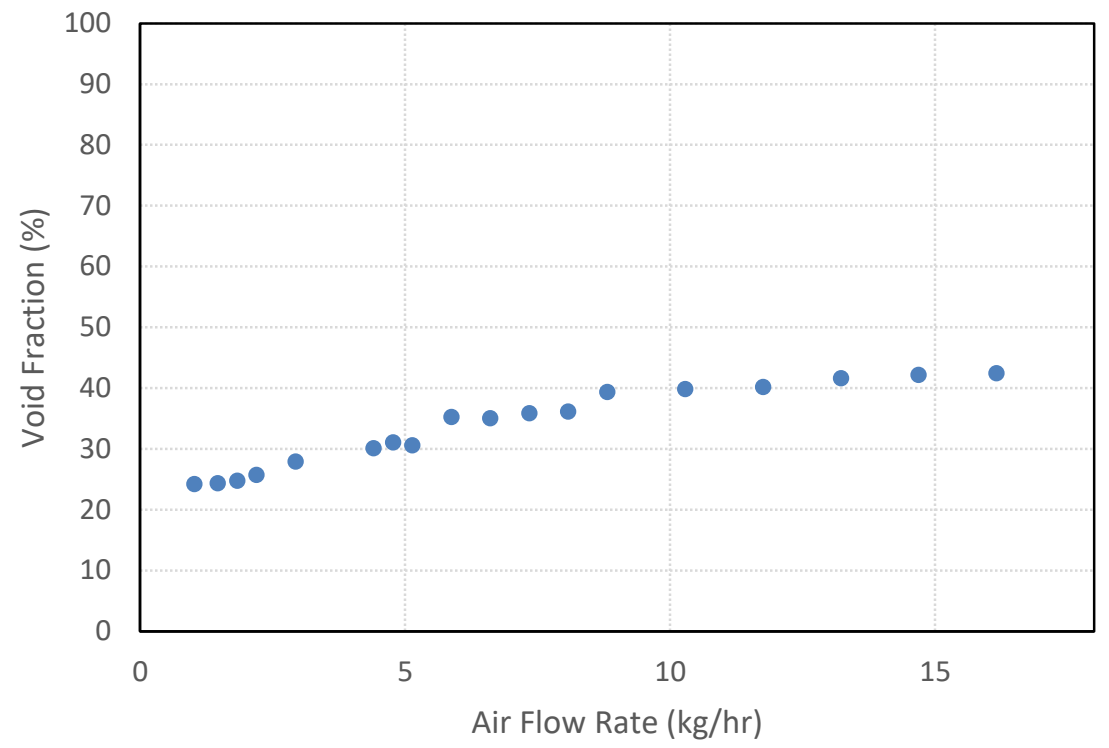

Fig. 3: Void Fraction of Airlift Pump Under Steady Dual Flow at 0.5 Submergence Ratio.

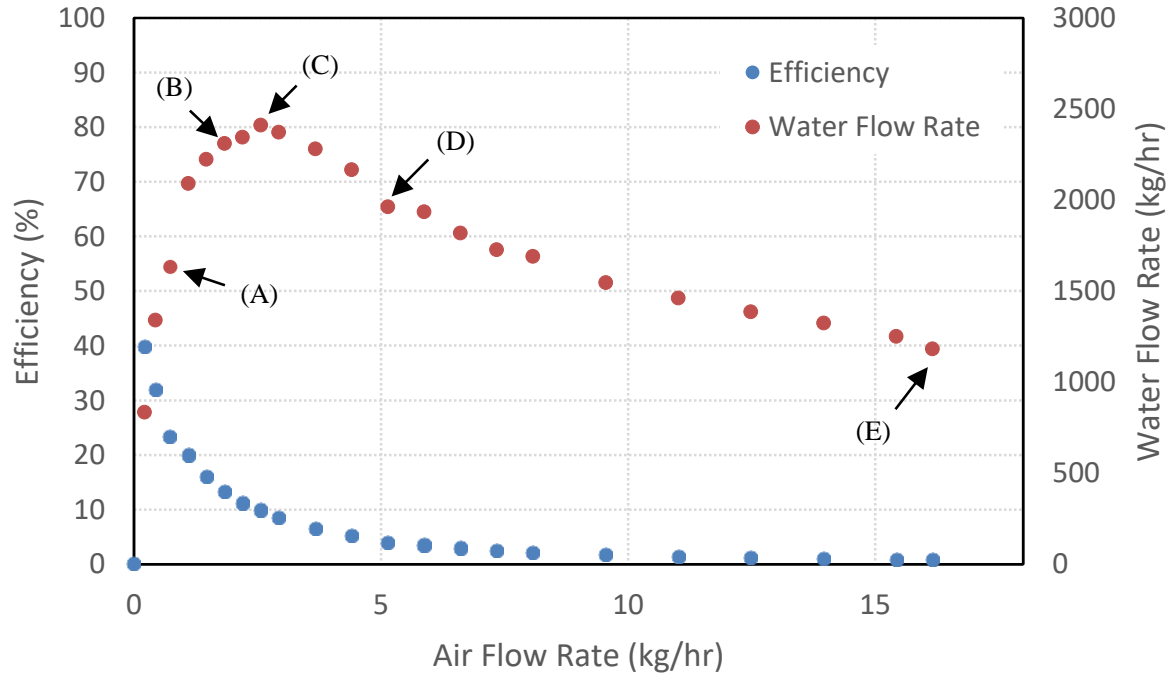

Fig. 4: Performance of Airlift Pump Under Steady Dual Flow at 0.9 Submergence Ratio 
A high-speed camera was used to collect instantaneous images of the various flow patterns observed at the 0.9 submergence ratio. As shown in Figure 4, four types of flow patterns are observed including bubbly, slug, churn and annular flow. The most optimal point should display a slug flow pattern and should correspond with the highest water flow rate value as seen in Figure 4. The different flow patterns at 5 different air flow rates, increasing from left to right, and varying in range are compared in Figure 6. It can be seen how the air and water flow mixture changes in bubble shape and behaviour as the air flow rates were increased. Figure 7 provides a sequence of the flow pattern collected when an airflow rate of $0.735 \mathrm{~kg} / \mathrm{hr}$ was being injected. These images show more of a bubbly flow pattern, as the air being injected is at the lower end of the range. Figure 8 depicts how the bubbles increase in size and become sparser as the airflow was increased to $1.8375 \mathrm{~kg} / \mathrm{hr}$. These sequences of images in Figure 9 were taken at an air flow rate of $2.5725 \mathrm{~kg} / \mathrm{hr}$ and show more turbulent water flow with the increase of bubbles. On the other hand, Figure 10 images show the conditions at air flow rate of $5.145 \mathrm{~kg} / \mathrm{hr}$ while Figure 11 represent air mass flow rate of $16.17 \mathrm{~kg} / \mathrm{hr}$. The increased air flow rate in these images is mirrored in the larger air pockets as seen in Figure 10, while, the turbulence increases as shown in Figure 11. This is because the higher void fraction percentage for those tests creates more waves that causes the annular to become more like the churn type.

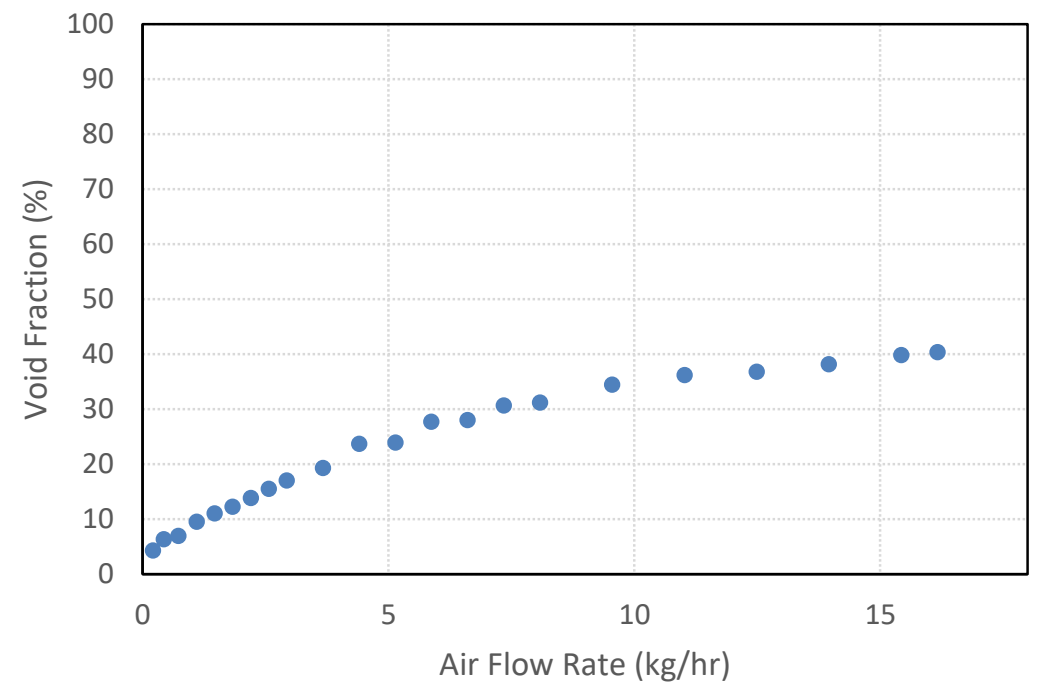

Fig. 5: Void Fraction of Airlift Pump Under Steady Dual Flow at 0.9 Submergence Ratio



(A)

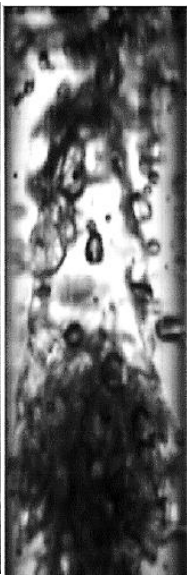

(B)



(C)
(D)
(E)

Fig. 6: Flow patterns at 5 different flow rates for 0.9 submergence as labelled in Fig 4 . 


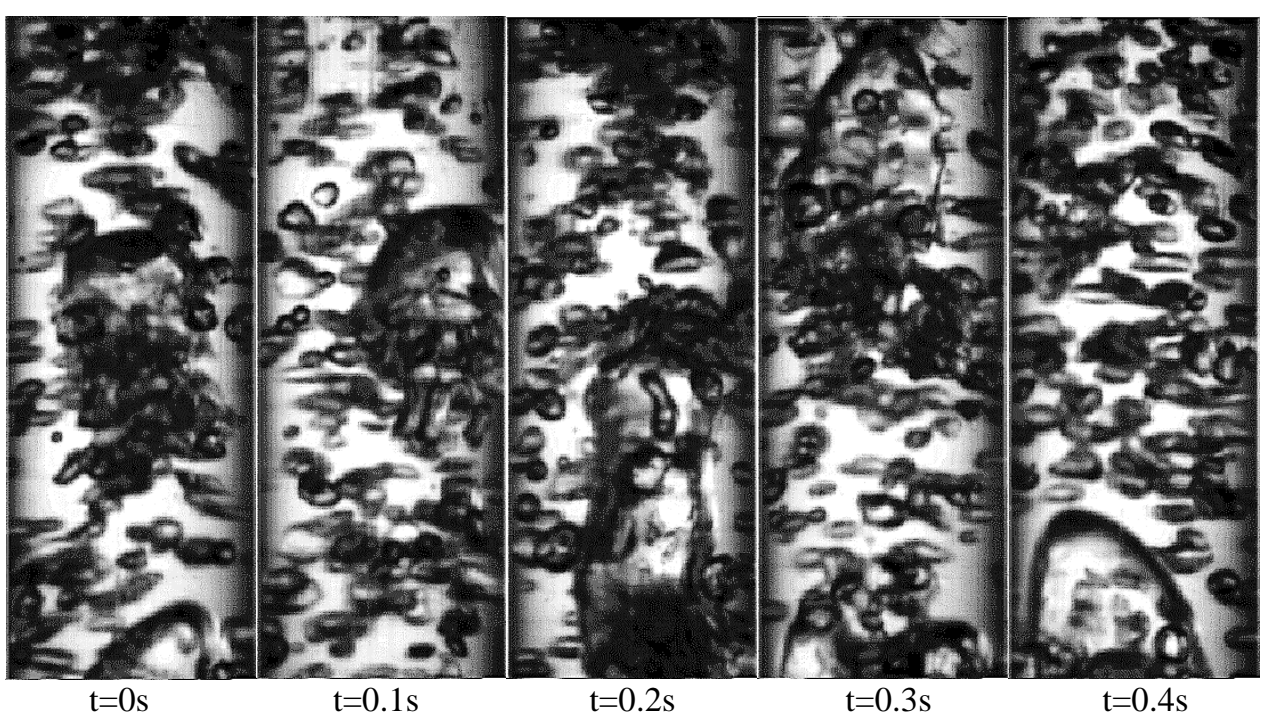

Fig 7: Flow pattern sequence observed at an air flow rate of $0.735 \mathrm{~kg} / \mathrm{hr}$

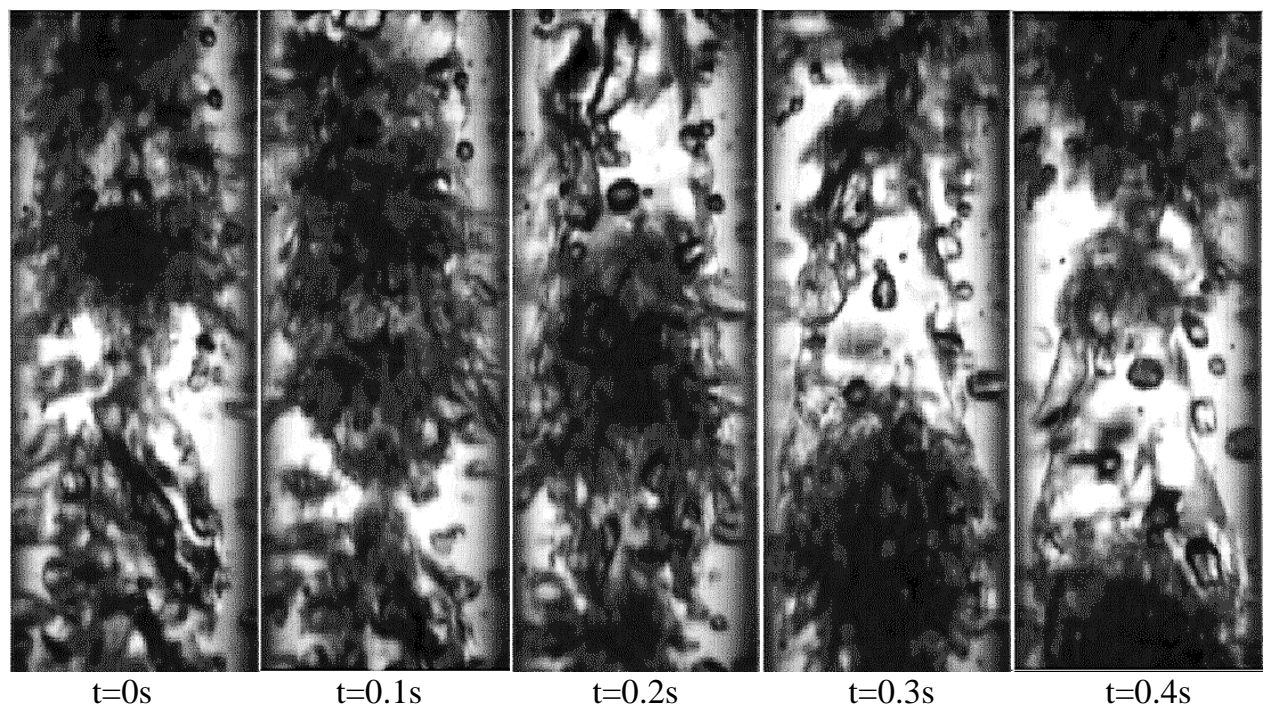

Fig. 8: Flow pattern sequence observed at an air flow rate $1.8375 \mathrm{~kg} / \mathrm{hr}$ 


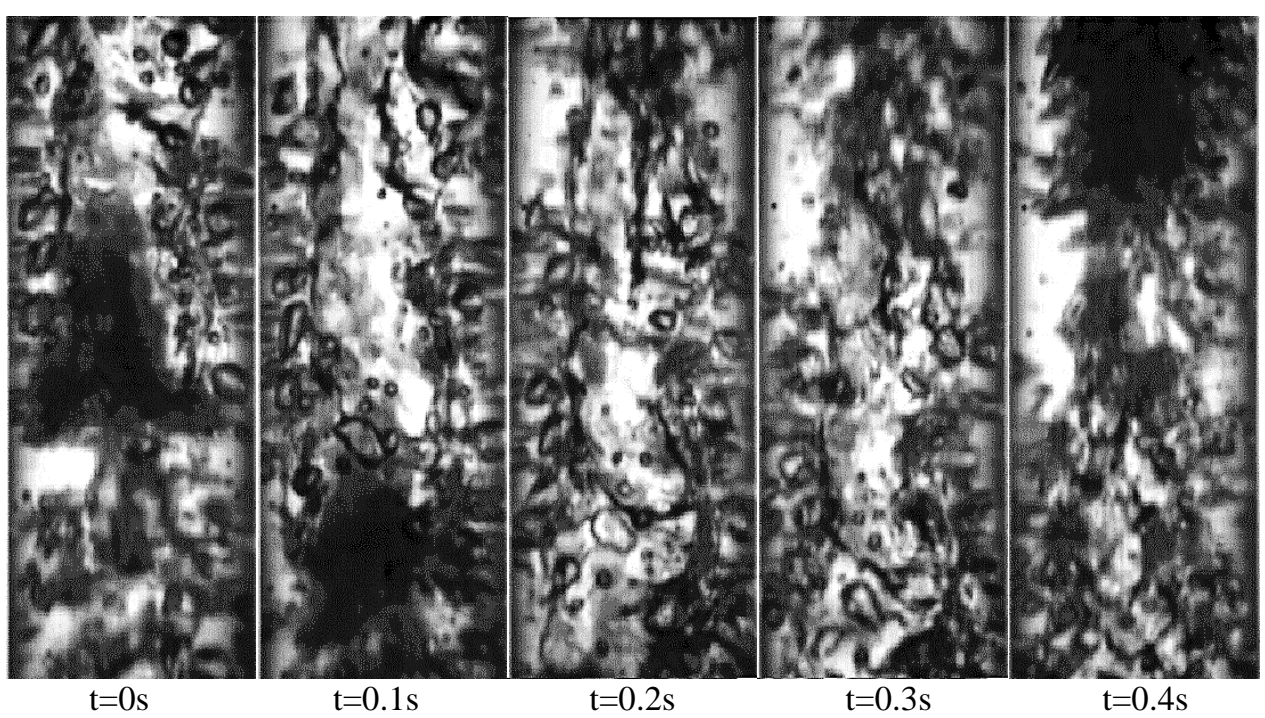

Fig. 9: Flow pattern sequence observed at an air flow rate $2.5725 \mathrm{~kg} / \mathrm{hr}$

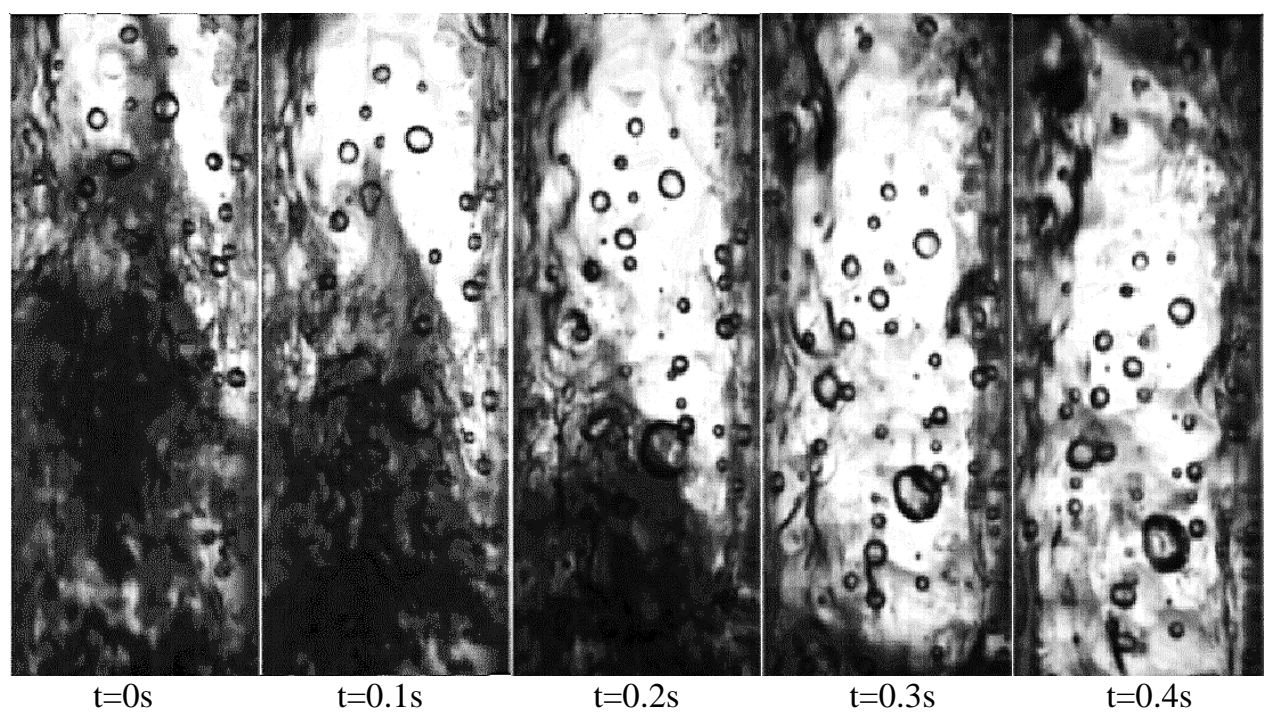

Fig. 10: Flow pattern sequence observed at an air flow rate $5.145 \mathrm{~kg} / \mathrm{hr}$ 


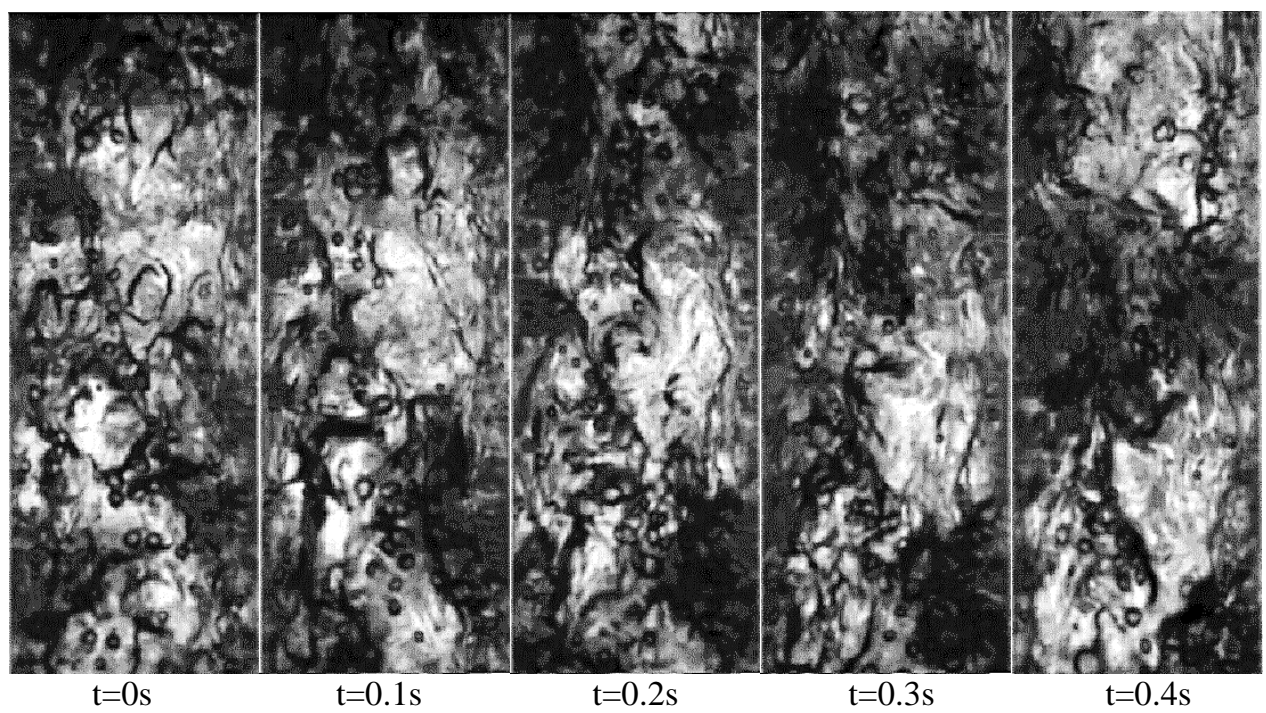

Fig. 11: Flow pattern sequence observed at an air flow rate $16.17 \mathrm{~kg} / \mathrm{hr}$

\section{Conclusion}

The results indicate that a higher submergence ratio results in a higher performance from the system and the maximum performance was found to be in the slug flow pattern region. The performance curves yielded an increase in water flow rate as the airflow rate was increased, reaching its peak early on and subsequently gradually decreasing. The efficiencies calculated using Nicklin's [5] equation showed that the air lift system to be more efficient prior to the peak performance value, decreasing steadily afterwards. It was also observed that flow pattern has a strong effect over performance, with the slug flow being the most desirable pattern. Moreover, the void fraction signal was found to be useful in interpreting the operational behaviour of the two-phase in the pump riser.

\section{Acknowledgements}

The authors wish to acknowledge the support received from the Ontario Ministry of Agriculture and Rural Affairs (OMAFRA) under the Gryphon's LAAIR (Leading to Accelerated Adoption of Innovative Research) grant.

\section{References}

[1] W. H. Ahmed, and H. M. Badr, "Dual-Injection Airlift Pumps: An Enhanced Performance Dual-Injection Airlift Pump: An Enhanced Performance," Particulate Sci, Techno., vol. 6351, no. February, 2016.

[2] F., Hitoshi, O., Satoshi and T., Hirohiko, "Operation performance of a small airlift pump for conveying solid particles,," J. Energy Resource Technol., vol. 125, pp. 17-25, 2003.

[3] D., Hu, C. L., Tang, S. P., Cai, F. H. and Zhang, "The Effect of Air Injection Method on the Airlift Pump Performance," J. Fluids Eng., vol. 134, no. 11, p. 111302, 2012.

[4] S. Z., Kassab, H. A., Kandil, H. A., Warda, H. A. and W. H., Ahmed, "Experimental and Analytical Investigations of Airlift Pumps Operating in Three-Phase Flow," Chem. Eng. J., vol. 131, pp. 273-281, 2007.

[5] D. J. Nicklin, "The Air-Lift Pump: Theory and Optomisation," Chem. Eng. Res. Des., vol. 41, 1963.

[6] W. H. Ahmed, "Capacitance sensors for void-fraction measurements and flow-pattern identification in air-oil twophase flow,” IEEE Sens. J., vol. 6, no. 5, pp. 1153-1163, 2006. 